\title{
Sentipensar la pandemia COVID-19 desde la sistematización de la experiencia en Trabajo Social: reflexiones del profesor Oscar Jara Holliday
}

\author{
Elia Sepúlveda-Hernández \\ Doctora en Educación/Pedagogía Social. Licenciada en Trabajo Social. \\ Universidad Santo Tomás. La Serena, Chile \\ https:/ / orcid.org/0000-0001-6474-4226・eliasepulvedahe@santotomas.cl
}

Resumen

El artículo es una reflexión teórica sobre Sistematización y Trabajo Social (TS) durante la pandemia COVID-19 y los desafíos disciplinares que impone el nuevo escenario social. Se trata de un TS en la primera línea de lucha, con cambios radicales en el quehacer profesional y los procesos de formación. Dichas transmutaciones globales, contienen un cúmulo de experiencias necesarias de registrar para construir el TS del futuro. A partir de una entrevista realizada al profesor Oscar Jara H., se pone en valor la sistematización como recurso metodológico para sentipensar y racionalizar este momento histórico.

Palabras clave: Sistematización; Pandemia COVID-19; Trabajo Social.

Recibido: 28/09/2020 | Aprobado: 06/11/2020 |Publicado: 01/01/2021

(c) (1) (2) Esta obra está bajo una Licencia Creative Commons Atribución-NoComercialCompartirIgual 4.0 Internacional.

¿Cómo citar este artículo? / How to quote this article?

Sepúlveda-Hernández, E. (2021). Sentipensar la pandemia COVID-19 desde la sistematización de la experiencia en Trabajo Social: Reflexiones del profesor Oscar Jara Holliday. Prospectiva. Revista de Trabajo Social e intervención social, (31), 131-150. doi: 10.25100/ prts.v0i31.10653. 
Sepúlveda-Hernández

\title{
Feeling and Pondering the COVID-19 Pandemic through the Systematization of an Experience in Social Work: Reflections by Professor Oscar Jara Holliday
}

\begin{abstract}
The late opportunities that systematization represents for Chilean social work are the result of a slow process of recognition of its potential as a knowledge construction proposal, originated in the adverse conditions derived from the national context and from the academic undervaluation that it has had to face throughout its theoretical and methodological development. In such a framework, this article aims to present the main antecedents of the historical development of systematization in Chile in order to understand, in perspective, the current disadvantageous position it occupies in the country.

Keywords: Systematization; COVID 19 pandemic; Social Work.

Sumario: 1. Introducción, 2. Reflexión teórico-conceptual, 2.1 El coronavirus como un espejo de lo que somos y lo que seremos, 2.2 Coronavirus y Trabajo Social situado en la primera línea de lucha, 2.3 Sistematizar desde la experiencia: Reflexiones del profesor Oscar Jara H., 3. Conclusiones, 4. Referencias bibliográficas.
\end{abstract}




\section{Introducción}

El coronavirus, como tantos otros virus que afectan la salud humana, deja en evidencia las vulnerabilidades, las injusticias sanitarias y las ineficientes políticas públicas a la hora de distribuir las oportunidades de desarrollo. La pandemia COVID-191 no es solo un problema médico, sino que es profundamente social en la medida que afecta de manera diferenciada a las personas más pobres y marginadas del mundo. Según cifras del Center for Systems Science and Engineering (CSSE, 2020) de Johns Hopkins University, son casi 73 millones de personas infectadas por SARS-CoV-2 y aproximadamente 1.600 .000 muertes registradas en todo el mundo ${ }^{2}$. El virus ha sido menos agresivo si se compara con los 20 y 50 millones de personas muertas alrededor del mundo con la gripe española (1918-1920), sin embargo, genera alteraciones y desafíos globales de relevancia para el Trabajo Social y las ciencias sociales.

Las alteraciones de movilidad y acceso a derechos que causan las formas de control del virus, generan múltiples afecciones que eran impensadas. Cierre de fronteras, escuelas de todo el mundo sin funcionar por largos meses, mascarillas como un accesorio obligatorio a costa de multas, servicios fúnebres con asistencia limitada y la distancia social como "la nueva normalidad".

A partir de las consecuencias de la pandemia y otros factores sociopolíticos y económicos, el Programa de Naciones Unidas para el Desarrollo (PNUD, 2020a), estima que 71 a 100 millones de personas vuelvan a caer nuevamente en situación de extrema pobreza durante el 2020. A su vez, la atención en el coronavirus disminuye las fuerzas en el combate de otras enfermedades de alta prevalencia, como el VIH, la tuberculosis o la malaria. Por ejemplo, según indica The Global Fund (2020), un 85\% de programas contra el VIH que funcionan en 106 países, han sufrido interrupciones en sus servicios y unos 117 millones de niños y niñas podrían dejar de recibir la vacuna contra la tuberculosis.

Desde la incorporación del indicador de desarrollo humano global (IDH) en el año 1990, el año 2020 representa el mayor retroceso en las medidas de acceso a educación, salud y condiciones de vida. En la Figura 1, es posible apreciar el nivel de retroceso estimado del INH en el mundo:

${ }^{1}$ La abreviatura denota "CO" para corona, "VI" para virus, "D" enfermedad y "19" como el año en que la enfermedad se hizo visible por primera vez. El virus que causa la COVID 19 ha sido nombrado como SARS-CoV-2 y está dentro de los virus que causan el "síndrome respiratorio agudo severo".

${ }^{2} \mathrm{Al} 14 / 12 / 2020$ 
Sepúlveda-Hernández

Figura 1. Estimación de Índice de Desarrollo Humano ajustado para COVID-19.

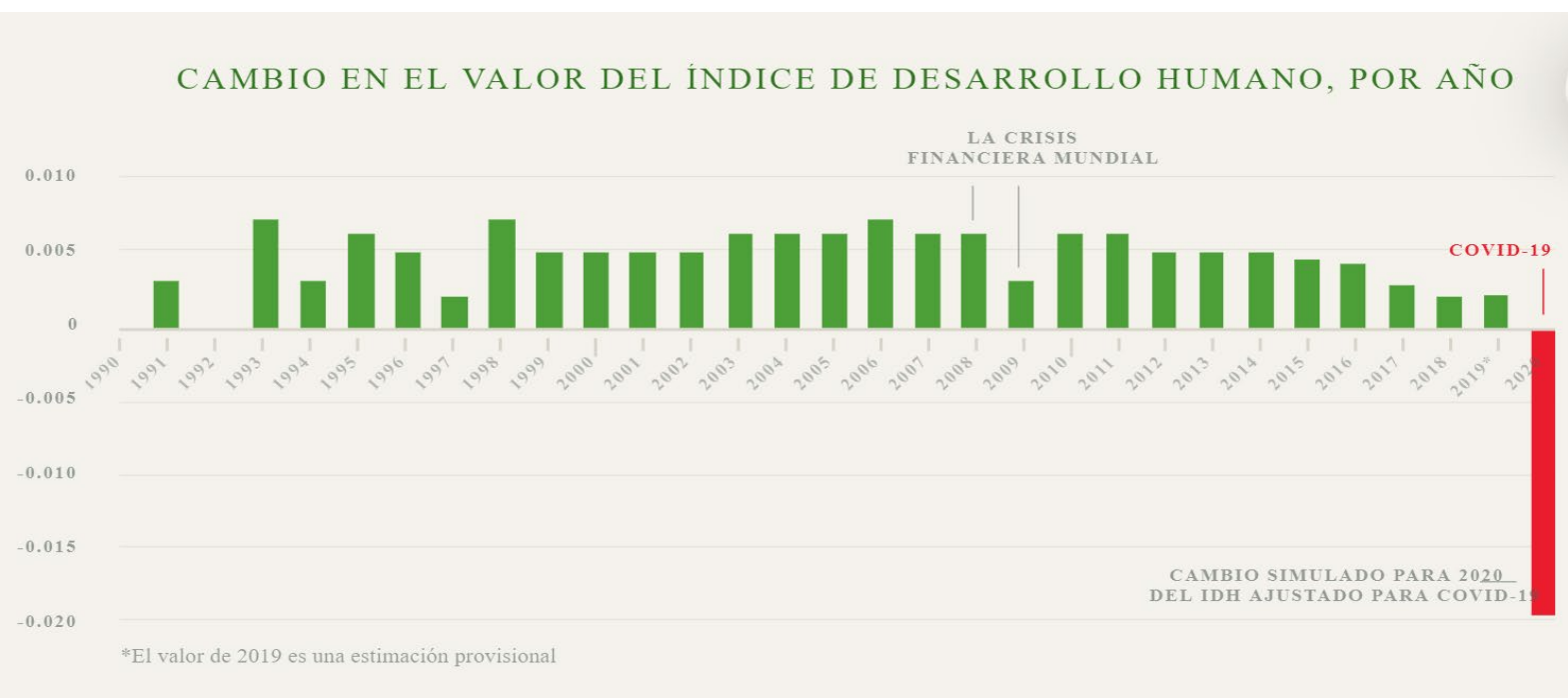

Fuente: (PNUD, 2020b).

Según la Organización para la Naciones Unidas (ONU, 2020), más de mil millones de personas en el mundo viven en asentamientos precarios e informales, son lugares que carecen de acceso a servicios higiénicos básicos y agua potable. A su vez, la Organización Internacional del Trabajo (OIT), estima que la crisis económica por coronavirus provocará que 800 millones de personas no puedan cubrir sus necesidades básicas y 135 millones padezcan niveles críticos de hambre. En el caso de las mujeres, la situación es más crítica si se consideran problemáticas como el aumento de la violencia y la carga doméstica durante el confinamiento (Rivera, Yu-Chieh, Pavez-Esbry y Dugarova, 2020).

A su vez, el personal sanitario y social que se encuentra en la primera línea de lucha contra el virus son en su mayoría mujeres, siendo el Trabajo Social (en adelante TS) una profesión de alta demanda durante el afrontamiento de esta pandemia. La distribución de ayuda humanitaria, prestaciones de seguridad social y atención en crisis en contexto de COVID-19, exigen a la profesión un ritmo de acción que transformará el TS del futuro.

Desde una intervención social situada en la primera línea, son miles de trabajadoras y trabajadores sociales que gestionan y movilizan recursos, resiliencias y soluciones creativas frente a una contingencia que apareció de manera sorpresiva y sin aviso previo. Desde este trance histórico, surgen muchas experiencias que serán un valioso patrimonio teórico, ético e histórico del TS. Se trata de testimoniar este momento, con la convicción que desde la reflexión de la experiencia es posible avanzar hacia mejores formas de hacer TS. 
Sepúlveda-Hernández

En este desafío disciplinar histórico, la sistematización de la experiencia (JaraHolliday, 2013, 2015, 2020) se transforma en un recurso metodológico que otorga múltiples herramientas para generar conocimiento desde el coronatime. La sistematización forma parte de la tradición del TS de América Latina y abre el camino para elaborar conocimiento a partir de la práctica. Como plantea Aguayo (1992), "la sistematización permite una reflexión colectiva que va más allá de los problemas inmediatos. Ella posibilita revitalizar las prácticas, acumular conocimiento para actuar y comunicar la experiencia para que ella ocupe un espacio histórico y social" (p. 36).

Con el objetivo de poner en valor la sistematización como una alternativa de aprendizaje disciplinar que surge desde la realidad cotidiana del ejercicio profesional y no necesariamente desde las élites académicas (Tapella y Rodríguez, 2014), este artículo presenta las reflexiones del profesor Oscar Jara Holliday, quien abre un valioso espacio de reflexión respecto a estos tiempos y la vigencia de la sistematización en el panorama actual. A través de una entrevista, el profesor Oscar Jara se refiere a temas como intervención social, género y espacio virtual, entre otras cuestiones.

Oscar Jara H., es un sociólogo y educador de Latinoamérica y referente mundial en temas de sistematización, alfabetización y educación popular. Durante su vida, ha estado en varias "primeras líneas de lucha", como por ejemplo, la revolución sandinista en Centroamérica.

Desde los intensos caminos de la educación popular -con las influencias directas del teólogo de la liberación, Gustavo Gutiérrez y el pedagogo Paulo Freire- el profesor Oscar Jara ha desarrollado una importante trayectoria académica y sus aportaciones teóricas son leídas en muchas escuelas de Trabajo Social. Actualmente, es director general del Centro de Estudios y Publicaciones Alforja en Costa Rica ${ }^{3}$ y presidente del Consejo de Educación Popular de América Latina y el Caribe4.

A través del diálogo de saberes con el profesor O. Jara, este artículo busca aportar al pensamiento del TS desde la pertinencia de la sistematización de la experiencia. Como plantea Jara-Holliday (2020), es necesario impulsar procesos de democratización del conocimiento, tanto en su producción como en su flujo, desde la valoración de la novedad de los hechos recientes que permitan trascender lo descriptivo-mecánico. Para así, transitar hacia nuevos marcos interpretativos desde las emociones, el sentipensamiento y el diálogo colectivo.

\footnotetext{
3 http://www.cepalforja.org/

4 http:/ / ceaal.org/v3/
} 


\section{Reflexión teórico-conceptual}

La reflexión teórica se organiza en tres apartados. El primero aborda el fenómeno de la pandemia COVID-19, a partir de las consideraciones de teóricos contemporáneos de relevancia mundial. A través de estos planteamientos, se problematiza la pandemia desde sus complejidades políticas y sociales, con énfasis en las consecuencias y transformaciones que provoca.

El segundo apartado, reflexiona sobre el TS durante la pandemia y los desafíos disciplinares que impone el nuevo escenario social. Se trata de un TS en la primera línea de lucha, con cambios radicales en el quehacer profesional y los procesos de formación. Dichas transmutaciones globales, contienen un cúmulo de experiencias necesarias de registrar para construir el TS del futuro.

Los dos apartados anteriores son el preámbulo para la parte central de este artículo. En la tercera sección, se presentan las reflexiones del profesor Oscar Jara H., respecto al valor de la sistematización como recurso metodológico para sentipensar este momento histórico. Se trata de una entrevista abierta a partir de preguntas eje que orientan el diálogo de saberes.

\subsection{El coronavirus como un espejo de lo que somos y lo que seremos}

El Programa de Naciones Unidas para el Desarrollo (PNUD, 2020a), considera que la pandemia por coronavirus es el mayor desafío que enfrenta la sociedad global luego de la Segunda Guerra Mundial. Diversos estudios de distintas partes del mundo, aportan interesantes reflexiones que instalan puntos de vista útiles a la hora de problematizar los impactos y consecuencias de esta pandemia. Son miradas que inyectan claridad para navegar por las incertidumbres de estos tiempos, así como también, proyectan las transformaciones que llegaron para quedarse.

El filósofo surcoreano Byung-Chul Han afirma que esta pandemia revela la característica no democrática de la vulnerabilidad humana, donde hasta la muerte se supedita al estatus social y los fallos de una sociedad profundamente desigual. Quienes se exponen más al virus, son aquellas personas trabajadoras que se someten a estructuras débiles de protección laboral y no pueden acceder al teletrabajo ni a condiciones seguras de movilidad o acceso sanitario (Sigüenza y Rebollo, 2020). Además, se levantan nuevas formas de control social, como la vigilancia biopolítica digital, que hará de nuestro cuerpo un espacio de patrullaje digital al servicio de disciplinas biopolíticas impuestas en contextos no democráticos. El autor reflexiona respecto a la disyuntiva entre sobrevivencia y vida plena, en el sentido que por sobrevivir al coronavirus las personas sacrifican aspectos relevantes para disfrutar de la vida, como por ejemplo la sociabilidad, el encuentro con la familia y los espacios comunitarios. Se limitan incluso derechos sociales fundamentales a través de 
Sepúlveda-Hernández

sistemas de vigilancia policial que, por ejemplo, abundan en América Latina a través de toques de queda y decretos de zona de catástrofe que aumentan las atribuciones de policías y Fuerzas Armadas (Byung-Chul Han, 2020).

El filósofo eslovaco Slavoj Žižek (2020), aborda otro aspecto relevante a la hora de entender las características de la COVID-19. Se trata del desencadenamiento de otra epidemia que se asocia a un virus ideológico que estaba latente y ahora se hace evidente: "noticias falsas, teorías de conspiración paranoicas, explosiones de racismo" (p. 21). En este sentido, las cuarentenas parecen ser no solo un resguardo frente al virus, sino también frente a otras amenazas a las identidades nacionalistas e individuales. El espacio virtual se consolida como una "zona segura" de coronavirus, pero expone a la población a otro tipo de virus digitales que también son muy destructivos. O sea, la sensación de amenaza llegó para quedarse.

Naomi Klein (2020), advierte que comienza a surgir una doctrina del shock pandémico en donde el aislamiento físico no tiene como único objetivo el salvar vidas, sino que también sirve como un "laboratorio viviente para un futuro permanente y altamente rentable sin contacto" (párr. 6). Los hogares han dejado y dejarán de ser un espacio personal/exclusivo y a través de la conectividad digital de alta velocidad, mutarán hacia un multi espacio: escuela, trabajo, gimnasio o hasta consultorio médico. Sin embargo, la llegada de la inteligencia artificial para organizar la vida de manera digital, se sostiene sobre millones de personas trabajadoras pobres y anónimas que desde almacenes, fábricas, minas y plantas de procesamiento, permiten el engranaje de este sistema en modelación. Si alguna vez las sociedades tuvieron dudas sobre la pertinencia de la vida telemática y a través de una pantalla, esas dudas han quedado en jaque pues la pandemia impone pánicos y amenazas que justifican esta forma de formatear y controlar la vida cotidiana y privada.

Se trata de un virus que se mueve a nivel global por sobre las fronteras nacionales y demuestra la precariedad de la sociedad humana de este siglo. Judith Butler (2020), plantea esta precariedad desde los sistemas de protección social existentes. La autora afirma que la unidad familiar en confinamiento, aparece como el principal refugio al virus, sin embargo, una vasta población no tiene hogar y permanecen en la calle o asentamientos precarios, bajo condiciones de habitabilidad y hacinamiento que expande el virus de manera acelerada. Las decisiones político-sanitarias de los gobiernos para afrontar la pandemia son confusas y muchas veces orientadas por criterios económicos donde incluso las vidas humanas y la muerte se deciden desde el criterio costo-beneficio. Frente a este contexto problemático, esta pandemia tendrá un impacto en las formas de pensar la igualdad, la interdependencia global y las obligaciones mutuas. 
Sepúlveda-Hernández

A partir de una mirada con un fuerte sello ecocéntrico, Rita Segato (2020) afirma que esta pandemia es una "irrupción de lo real", esto es, el reconocimiento de nuestra "Historia Natural, la marcha azarosa de la naturaleza, sus desdoblamientos contingentes, su deriva. Organismos se consolidan, duran y desaparecen. Nuestra especie seguirá ese destino incierto también o, con suerte improbable, tendrá la longevidad de la cucaracha" (párr. 4).

La autora afirma que aun si el virus resultó de la manipulación humana en un laboratorio, es de todas formas un evento de la naturaleza que nos recuerda que somos parte de ella. La interacción bioquímica que establecemos en la biosfera, impacta las estructuras sociales que, bajo una lógica cartesiana, cosifican la vida y abren nuevas tensiones propias del antropoceno. Sin embargo, Segato (2020) considera que estas interacciones naturales intrínsecas, son en esencia impredecibles y están por sobre los controles y orden antrópico. Lo anterior se transforma en un problema para el mundo colonial-moderno, que teme a lo que no puede controlar y predecir. El SARS-CoV-2 irrumpió en la escena de Occidente y atacó a las principales potencias mundiales, alcanzando a gobernantes, empresarios y famosos. O sea, el virus recordó que todos somos mortales.

\subsection{Coronavirus y Trabajo Social situado en la primera línea de lucha}

En el actual contexto de crisis y emergencia socio-sanitaria, el Trabajo Social enfrenta múltiples exigencias y desafíos que lo sitúan en una posición estratégica entre el Estado y las urgencias comunitarias. Tal como plantea la International Federation of Social Workers (IFSW), el TS tiene un papel esencial en la primera línea de lucha contra la propagación del virus en funciones claves como: 1) Asegurar que los grupos vulnerables se incluyan en las acciones de planificación y respuesta; 2) Organizar a las comunidades para asegurar el acceso a elementos esenciales como agua y alimentos, 3) Dinamizar y abogar por el funcionamiento de los servicios sociales, para que se mantengan abiertos y en apoyo activo a las comunidades; 4) Facilitar el distanciamiento físico y la solidaridad social; 5) Fortalecer los servicios sociales y sanitarios como protección esencial contra el virus.

Se trata de retos profesionales que no son solo sociosanitarios o comunitarios, sino que también instalan desafíos éticos frente a las situaciones de riesgo, incertidumbre y crisis que imperan en la zona de lucha. En un informe de la IFSW sobre dilemas éticos y TS durante la COVID-19, se reconoce el difícil escenario que enfrentan hoy las personas que ejercen el TS, quienes han debido tomar decisiones de intervención en situaciones sumamente difíciles e inesperadas, como por ejemplo, evaluaciones sociales sin un encuentro cara a cara y otros asuntos donde la orientación de los gobiernos o administradores es inexistente o confusa. Han debido inventar y encontrar nuevas formas de ayuda, sobre la marcha, desplegando recursos de apoyo emocional y material en condiciones de distanciamiento social, confinamiento y teletrabajo (Banks et al., 2020a). 
Sepúlveda-Hernández

Desde los aprendizajes que deja la experiencia, es relevante abrir procesos de reflexión en los cuales la deliberación ética permita re-mirar los principios, valores y acciones correctas del TS en el escenario actual y futuro. A pesar de que la capacidad profesional ha sido impactada por el agotamiento y emocionalidad que provoca esta crisis, es importante activar la vigilancia reflexiva de las acciones y procesos profesionales, para así, incorporar mejoras y reconducir (Banks et al., 2020b).

Si bien la pandemia está en pleno desarrollo y se prevé que aún queda mucha experiencia por recorrer, ya comienzan a aparecer las primeras publicaciones y evidencias científicas que abordan la COVID-19 desde la práctica del TS. Muchas de ellas, consideran las lecciones aprendidas a partir de las distintas realidades que esta emergencia plantea.

Con foco en los impactos y abordaje disciplinar de la pandemia, algunas de estas publicaciones se refieren a los aprendizajes profesionales relevantes que abordan asuntos como los desafíos y respuestas éticas del TS (Banks et al., 2020a; Miller \& Lee, 2020); el papel transformador del TS (Dauti, Dhëmbo, Bejko, Allmuça, 2020); voces de trabajadores sociales que trabajan con diversos colectivos vulnerables como refugiados (Nisanci, Kahraman, Alcelik y Kiris, 2020), personas adultas mayores (Angel \& Mudrazija, 2020; Henning-Smith, 2020; Omorogiuwa, 2020) o pacientes con coronavirus y sus familias (Levin-Dagan \& Strenfeld-Hever, 2020); duelo prolongado por COVID-19 y el papel del TS en procesos de reparación (Johns, Blackburn \& McAuliffe, 2020); experiencias de estudiantes de TS durante la pandemia, como por ej., la formación en línea (Firang, 2020; Gallagher, Doherty \& Obonyo, 2020; Papouli, Chatzifotiou \& Tsairidis, 2020; Smoyer, O'Brien \& Rodríguez-Keyes, 2020).

Se trata de artículos científicos muy recientes que generan conocimiento desde la perspectiva que el TS es una disciplina en constante aprendizaje y creación, aún más frente a una pandemia global que altera los diversos escenarios de la acción profesional. Como plantea Nissen (2020), el TS se hace y aprende en la comunidad, en las salas de tratamiento de hospitales, en los refugios para las personas sin techo, en las escuelas, en los servicios sociales estatales y en incontables espacios críticos e impactantes. Espacios de lucha desde los cuales se atajan las severas fallas del neoliberalismo y se hace frente a las injusticias sociales, sanitarias y ambientales. Es por tanto, una praxis profesional que hoy más que nunca requiere plantearse preguntas ambiciosas para enfrentar el futuro del mundo y de la profesión.

La COVID-19 no solo cambiará el mundo, sino también la profesión, ¿Está el Trabajo Social preparado para el futuro y es capaz de participar en este discurso? ¿Cómo desafiará, involucrará, mejorará y transformará el Trabajo Social? ¿Se necesitarán nuevas herramientas, nuevas ideas, nuevas mentalidades para trasladarse a un mundo poscovid-19? ¿Qué nuevas herramientas, qué inventos sociales, qué nuevas políticas pueden surgir? (Nissen, 2020, p. 17) 
Sepúlveda-Hernández

Dichas preguntas -y tantas otras que resuenan en diversas geografías del TSencuentran en la sistematización un espacio prolífico para poner la realidad entre paréntesis, en signos de interrogación que permitan pensar colectivamente los retos, roles y competencias profesionales que se ajusten a los tiempos post coronavirus.

\subsection{Sistematizar desde la experiencia: reflexiones del profesor Oscar} Jara $\mathbf{H}$.

A continuación, se presenta la entrevista realizada al profesor Oscar Jara. La entrevista se organiza en 5 preguntas abiertas que abordan temas como la experiencia de la pandemia en Latinoamérica, los retos metodológicos de sistematizar en contextos de distanciamiento social y/o virtuales. Así como también, temas que se relacionan con la cuestión de género en TS y recomendaciones para docentes que dinamizan procesos de formación en TS.

Entrevistadora: Como ha vivido la emergencia sanitaria en su territorio y desde allí, ¿Qué reflexiones le surgen cuando mira el mundo global en tiempos de coronavirus?

Profesor Oscar Jara: La presencia del COVID-19 en nuestros países ha implicado poner en evidencia muchos aspectos que caracterizan nuestras sociedades latinoamericanas: en primer lugar, ha visibilizado todas las desigualdades existentes producidas por las políticas neoliberales y que significaron reducción de presupuestos de salud y educación favoreciendo la privatización de estos servicios y, por lo tanto, afectando los derechos de toda la población. Nunca como ahora se ha hecho más evidente la necesidad de contar con una educación y una salud pública universal, gratuita, inclusiva y de calidad. Las medidas de aislamiento físico y confinamiento han visibilizado la precariedad de las condiciones habitacionales en grandes barrios populares, incapaces de ser espacios adecuados para habitar en ellos. Los cambios a formas de comunicación virtuales para continuar con los ciclos escolares han demostrado la enorme disparidad existente en cuanto acceso a conectividad por internet, así como la falta de equipos de computación en los hogares y, cuando se ha querido utilizar la vía de la mensajería telefónica, las pocas posibilidades que tiene mucha gente de costear el tiempo de comunicación que implica. Por otra parte, el enorme porcentaje de población que vive al día con empleos informales, ha implicado la imposibilidad de mantener el confinamiento, adicionalmente a la disminución radical de opciones para obtener un ingreso con ventas ambulantes o trabajos esporádicos. Esto ha afectado particularmente a las poblaciones migrantes que en otros países o en grandes ciudades han quedado a la deriva absoluta en sus condiciones de vida. Todo esto ha implicado todavía un mayor impacto en las mujeres, quienes -en función de sus roles tradicionales- han tenido que multiplicarse aún más para atender sus hogares, conseguir algún ingreso y apoyar a sus hijas e hijos con el estudio. Los casos de violencia contra las mujeres han crecido aún más, mostrando con mayor crudeza la vulnerabilidad de sus vidas cotidianas. 
En segundo lugar, estas condiciones de desigualdad no solo han quedado más visibles, sino que se han agravado y se agravarán más con la continuidad de la situación de pandemia, lo que nos hace prever un escenario de mayores tensiones, ante las cuales las políticas de la mayoría de los gobiernos han mostrado su inoperancia e ineficiencia, sea para garantizar condiciones mínimas de sobrevivencia, como para responder a las demandas crecientes de la mayoría de la población. La presión de las empresas por salvar "su economía" y tasas de utilidades ha ido creciendo para influenciar las decisiones oficiales. Esto ha devenido en varios países en el aumento de actuaciones autoritarias y de represión hacia las legítimas protestas de la población.

En tercer lugar, hay un impacto grande en la subjetividad de los sectores populares producto de la incertidumbre, el temor, la inseguridad, el aislamiento y la percepción de abandono por parte de las entidades gubernamentales. La prolongación de esta situación afecta en particular a las trabajadoras y trabajadores de la salud y educación que están en la línea diaria de atención social y colectiva, como también a pacientes de otras enfermedades o a la población estudiantil que va viendo pasar los meses sin contacto cercano con sus coetáneos, sin espacios de socialización o recreación colectivas. También afecta a los movimientos y organizaciones sociales populares que se encuentran sin poder realizar sus tradicionales formas de acción organizativa y de movilización y deben reinventarse ante esta situación. Juega también un impacto importante en la subjetividad la percepción de incapacidad de los gobiernos para enfrentar la situación de una crisis que se prolonga o se agrava, generándose mayor descrecimiento y deslegitimación, también con respecto a los discursos oficiales y la complicidad de medios informativos con las presiones que realizan las clases empresariales para buscar mantener sus privilegios ante las medidas que se puedan tomar.

En cuarto lugar, y no por eso menos importante, está también la otra cara de esta situación: la que proporcionan las múltiples experiencias de apoyo mutuo, trabajo colectivo, solidaridad, intercambio generoso, reflexiones críticas y propuestas basadas en el interés común y defensa de las mayorías de la población: ollas comunes, entrega de alimentos de organizaciones campesinas a poblaciones urbanas, proyectos de economía solidaria, iniciativas de acción cultural y apoyo mutuo entre artistas populares, debates y seminarios nacionales e internacionales utilizando las tecnologías de información y comunicación más allá de ser espacios de emisión para constituirse en espacios de intercambio, discusión y acción colectiva. Por todos nuestros países en los barrios, comunidades campesinas, comunidades indígenas, vemos interesantes iniciativas creativas que han surgido como respuesta autogestionaria ante la crisis. Ellas nos muestran que sí es posible otra manera de producir, de comercializar, de consumir, diferente a la lógica dominante que ha caracterizado la visión impuesta por el pensamiento capitalista neoliberal en nuestros países. Estas experiencias, múltiples y tal vez de impactos todavía localizados, nos muestran que hay caminos posibles para construir una sociedad afincada en una ética del cuidado de 
Sepúlveda-Hernández

la vida, que ponga por encima de todo a la gente y sus condiciones de existencia material y espiritual. Que sí es posible construir relaciones horizontales, democráticas, respetuosas de las diversidades que confrontan la matriz cultural patriarcal y capitalista que hasta hoy ha sido hegemónica. Que sí es posible actuar con una racionalidad y una perspectiva ecofeminista que coloque la ética del cuidado sobre las personas y el planeta por encima de la voracidad extractivista y las posturas racistas y excluyentes. Identificar estas experiencias, buscar su intercomunicación y animar su articulación, sistematizarlas y construir políticas y propuestas de mayor alcance a partir de las realidades que se generan, es una tarea imprescindible en estos momentos, tanto en el ámbito local, como nacional, interregional y global. Otro mundo, sí es posible.

Entrevistadora: ¿Cómo sistematizar desde las distancias y fronteras distanciamiento social- que instala la pandemia? ¿Qué desafíos metodológicos enfrenta el proceso de sistematización cuando los espacios virtuales son hoy las esferas de la intervención social?

Profesor Oscar Jara: El criterio básico es el de precisamente buscar romper las distancias, fronteras y barreras. Puede incentivarse -y es importante- el distanciamiento físico, pero eso no debe implicar que haya un distanciamiento social, aislarnos de las necesarias formas de socialización y mirada colectiva. La trampa de la salida individual que está instalada en la mentalidad neoliberal, es precisamente el primer escollo que tenemos que superar.

Por eso la sistematización de experiencias puede jugar un rol aún más importante que antes de la pandemia. Entendiendo que no se trata simplemente de "sistematizar información", es decir, agrupar, clasificar, catalogar datos, sino de "Sistematizar Experiencias": interpretar críticamente nuestras experiencias vividas para extraer de ellas aprendizajes significativos. La fuerza de la sistematización de experiencias reside precisamente en que genera una reflexión crítica desde y para los procesos reales, constituyéndose en un ejercicio de teorización desde las prácticas que se alimenta de ellas y a ellas revierte. Su fuerza, además, deviene en que somos los mismos practicantes quienes realizamos el ejercicio de sistematización de experiencias, por lo que está al alcance de todas las personas, si se tienen los métodos, técnicas y procedimientos adecuados para hacerla.

No toda reflexión sobre la acción constituye una sistematización de una experiencia. Es necesario un proceso organizado y coherente que se inicia formulando una propuesta de sistematización, donde el objetivo sea definido y claro, pensando en la utilidad que tendrá ese conocimiento consistente construido desde la práctica, en una perspectiva transformadora. Es decir, no que sirva simplemente para dar cuenta del quehacer realizado, sino que sirva para alimentar el futuro de la propia experiencia o inspirar a otras similares, como un aporte para su mejora o su transformación. Si la sistematización de experiencias 
significa apropiarse del pasado, es, principalmente, para poder apropiarnos del futuro que queremos construir.

Es necesario, además, basándonos en todos los registros posibles obtenidos durante el proceso de la experiencia, reconstruir rigurosamente lo ocurrido y lo realizado: el trayecto seguido y la intervención de los distintos actores y factores durante ese recorrido. Ahí surgirán los principales aspectos recurrentes o también las discontinuidades que marcan ese trayecto, las interrelaciones y los factores más decisivos que explican el porqué de la experiencia. Para ello es necesario identificar categorías de análisis y momentos de síntesis. En definitiva, poder tomar distancia de lo vivido para obtener una mirada panorámica y comprensiva de nuestro quehacer y no simplemente la descripción narrativa de lo sucedido. Todo ello es base para la interpretación crítica y la obtención de aprendizajes significativos, que es lo más importante de la sistematización de una experiencia.

En estos tiempos de aislamiento físico hemos comprobado que es totalmente posible poner en práctica estos procesos, utilizando la tecnología virtual y generando procesos comunicativos aún a distancia. Que es posible formular planes y llevar adelante procesos de reconstrucción histórica e interpretación crítica, llevando a cabo momentos de intercambio y comunicación entre actores de las experiencias. Existen experiencias realizadas en estos meses donde, por ejemplo, se han realizado programas sonoros en forma de "podcast" a partir de testimonios o entrevistas con actores populares vía medios como el "chat" de Whatsapp o Telegram. Realización de conferencias virtuales en las que se ha podido estar presentes desde conexión telefónica. Incluso, yo mismo he realizado cursos en universidades apoyando metodológicamente la realización de procesos de sistematización que cada quien, o en equipos, han realizado.

En estas experiencias, por supuesto, ha jugado un papel importante la relación y el vínculo de confianza construido previamente en momentos de encuentros presenciales físicos. La relación personal "cara a cara", el abrazo, el intercambio de miradas, la comunicación gestual, el intercambio de una tarde de café, mate o guitarreada son insustituibles. Pero cuando esto se ha hecho, ya hay una base fundamental para sostener la comunicación virtual. Claro, una condición importante es no reducirse a utilizar pasivamente el medio tecnológico tal como nos lo tienen pautados quienes lo han producido, sino ampliar, con imaginación y creatividad sus posibilidades: por ejemplo, haciendo que el momento de encuentro virtual haya sido precedido por un ejercicio propio de elaboración de propuestas o aportes particulares via imágenes, frases claves, fotografías, canciones, vídeos, etc. de tal manera que ese momento sea parte de un proceso comunicativo, que, además, pueda continuar en las prácticas particulares. 
Sepúlveda-Hernández

Entrevistadora: Las cuestiones de género han sido un asunto complejo en esta pandemia. Las mujeres son uno de los colectivos sociales más afectados (aumento de la pobreza, violencia, desempleo, multi roles...) Siendo el Trabajo Social una profesión compuesta principalmente por mujeres que se encuentran en la primera línea de esta pandemia, ¿qué oportunidades aporta la sistematización a la visibilización, protagonismo y construcción de un quehacer profesional en clave antipatriarcal?

Profesor Oscar Jara: Como dijimos anteriormente, es fundamental identificar, visibilizar y analizar los impactos específicos de la pandemia en nuestros quehaceres. En el Trabajo Social, eso que señalas es muy claro, pues en la primera línea de atención en salud, educación y alimentación, por ejemplo, o en el trabajo con poblaciones más vulnerabilizadas como adultas y adultos mayores, personas con discapacidad, población migrante o refugiada, personas en situación de calle, jóvenes en riesgo social, niñez abandonada, etc. el rol de las mujeres trabajadoras sociales está siendo decisivo y fundamental. Claro, esto con un doble o triple impacto debido en muchos casos, a la persistencia de sus roles de subordinación con respecto a los varones, el sobreentendido que ellas son predestinadas a cuidar de la familia a costa de sí mismas, a la naturalización de esos roles dependientes y sacrificiales y también a subvalorar sus capacidades profesionales.

En ese sentido, sistematizar las experiencias de las mujeres trabajadoras sociales, por parte de ellas mismas, cruzando el análisis e interpretación con un enfoque de perspectiva de género, reforzando el análisis crítico respecto a la imposición de una matriz patriarcal y machista sobre la vida cotidiana y profesional para visibilizar, cuestionar, desnaturalizar esas visiones, es muy importante. En muchos análisis eso no se toma en cuenta, como si fuera indistinto que quienes llevan a cabo las tareas del Trabajo Social fueran hombres o mujeres o incluso población trans. Visibilizar esto, trabajarlo críticamente, denunciarlo y mover conciencia al respecto, es fundamental para resignificar y reconstruir los roles de género en nuestras sociedades, que son los espacios donde se cimentan los enfoques y relaciones de poder autoritario, excluyente y discriminador hacia las mujeres. En ese sentido, la sistematización de experiencias de Trabajo Social realizada por mujeres, que aborden siempre las relaciones y contradicciones de género presentes en las experiencias, puede ser un factor importante de empoderamiento y, por tanto, de transformación social, política y cultural que esta situación de pandemia podría -paradójicamente- ayudar a reforzar. 
Sepúlveda-Hernández

Entrevistadora: Algunos vaticinan que esta pandemia cambiará para siempre las formas de educarnos, de relacionarnos, de organizar las sociedades modernas. ¿Qué sistematizar de acá en adelante a partir de la realidad de América Latina? Me refiero a experiencias, procesos o ámbitos de la intervención social que son hoy urgentes y necesarios de sistematizar por su valor histórico.

Profesor Oscar Jara: Algo ya hemos mencionado. Pero creo fundamental rescatar la importancia y el peso que tienen las intervenciones de Trabajo Social en la vida cotidiana de los sectores populares latinoamericanos. Por supuesto superando la idea tradicional de asistencialismo (que no significa negar la importancia de la atención a las urgencias) para resaltar el papel ético, político y pedagógico que tiene la inmersión respetuosa en procesos comunitarios, barriales, organizativos, etc. También, mirando el aporte propositivo que supone no sólo atender una situación de emergencia, sino crear condiciones para su superación.

En este sentido me gustaría recuperar una reflexión que hicimos hace varios años en Centroamérica cuando tuvimos el impacto y la emergencia del Huracán Mitch en todos nuestros países y que se constituyó en la mayor tragedia regional que se había vivido en siglos en la región. En ese momento, en la Red ALFORJA y en coordinación con otras organizaciones, construimos una matriz de análisis respecto a "Paradigmas en casos de situaciones de emergencia", donde contraponíamos el paradigma tradicional, autoritario, vertical y asistencialista, a un paradigma crítico, de empoderamiento, horizontal y transformador. Estos paradigmas están en confrontación directa cuando se trata de procesos de Trabajo Social en situaciones de crisis.

Por ejemplo, en el paradigma tradicional la población afectada es considerada como víctima, dependiente de nuestra acción, como población "meta". En el paradigma crítico, son personas que tienen experiencias, potencialidades y capacidades para comprender y resolver los problemas. Mientras en el paradigma tradicional se atiende el corto plazo atendiendo la emergencia y luego retirándose cuando ha pasado, en el crítico se trabaja en el corto plazo construyendo capacidades para el mediano y el largo plazo, incorporando a la población en los diagnósticos, análisis y decisiones. Mientras en el paradigma tradicional las decisiones y tareas principales se asignan a los hombres adultos, dejando a las mujeres las tareas de apoyo o cuidado de la niñez, en el paradigma crítico todas las personas, no importando su condición de género o edad, participan de acuerdo a sus características. Igualmente pasa con la gestión de información: en el paradigma tradicional está centralizada en los "especialistas", en el crítico se busca socializar y compartir de forma transparente facilitando la comprensión consciente e informada de la población. 
Sepúlveda-Hernández

En otros aspectos también es claro identificar diferencias claves: en el paradigma tradicional se busca dar respuestas a personas individuales, que se manejan según criterios externos; en el crítico se busca fortalecer formas de organización democráticas, participativas y horizontales. Se rinden cuentas y se construyen modalidades de decisión colectiva que en el futuro fortalecerían las capacidades ciudadanas activas y responsables.

En definitiva, las situaciones críticas, como la actual pandemia ponen en cuestión los enfoques, los métodos, las técnicas y procedimientos que utilizamos en el quehacer del Trabajo Social, dependiendo de los cuales se refuerzan las incapacidades, vulnerabilidades y victimización de la población afectada o en las cuales -siguiendo una perspectiva de educación popular liberadora- se refuerza la construcción de capacidades, disposiciones, posturas proactivas y cualidades democráticas de las personas y grupos sociales como sujetos y no como objetos pasivos de atención.

Entrevistadora: ¿Qué recomendaciones haría a personas docentes universitarias que acompañan procesos de prácticas profesionales o dictan cátedras de investigación/evaluación/sistematización social?

Profesor Oscar Jara: La primera, sería un llamado a que analizáramos críticamente con qué paradigmas de acción estamos trabajando en esta u otras situaciones de emergencia y cuáles son los criterios con los que impulsamos nuestros proyectos y planes de acción, así como los vínculos con la población más afectada. Es una reflexión que deberíamos hacer como docentes, entre docentes y estudiantes y también entre las y los estudiantes. Generar una capacidad de cuestionamiento crítico de nuestro rol y los enfoques con los que realizamos Trabajo Social.

La segunda, que podamos desplegar toda nuestra creatividad para ir más allá de las limitaciones del momento, sean físicas, tecnológicas, de condiciones económicas o disposiciones subjetivas. Pensar en la generación de procesos de autonomía, autogestión, protagonismo y participación, ampliando al máximo las posibilidades de comunicación y contacto que tenemos.

La tercera, que revisemos cómo es que hemos construido vínculos con las personas, organizaciones e instituciones con las que trabajamos; qué niveles de confianza y relación mutua se han generado; qué niveles de tensión, contradicción o problemas han existido, etc. Pues desde la virtualidad será muy importante reforzar los vínculos que posibilitan continuar construyendo posibilidades, así como superar los aspectos conflictivos.

La cuarta, que incentivemos el registro riguroso de nuestro quehacer de tal forma que de tiempo en tiempo podamos hacer una reconstrucción del trayecto realizado durante la experiencia y eso nos sirva de base para sistematizar nuestro quehacer. Incentivar también 
Sepúlveda-Hernández

nuestras capacidades críticas y cuestionadoras que nos permitan desmontar los entramados autoritarios impuestos por las lógicas dominantes. De ahí podremos construir aprendizajes significativos para intercambiarlos con otros provenientes de otras experiencias y así construir propuestas democráticas y democratizadoras de mayor alcance para los caminos a seguir recorriendo.

En definitiva, saber que nuestro trabajo implica una postura ética de apuesta por el cuidado de la vida en el corto y largo plazo, que supone que nos dispongamos a colaborar en la construcción política de capacidades protagónicas en la gente que es precisamente la más vulnerable, para construir espacios de solidaridad y equidad. Cada actitud, cada proyecto, cada interacción es una posibilidad para construir esas capacidades, en la que nosotras y nosotros somos también, sujetos de una historia que queremos que sea realidad.

\section{Conclusiones}

Oscar Jara sitúa la acción profesional en la emergencia que provoca el virus, para desde allí, construir espacios democráticos desde el paradigma crítico. A partir de sus reflexiones, es posible concluir las siguientes ideas centrales:

- La sistematización no es solo un registro de la práctica, sino más bien, es interpretar críticamente nuestras experiencias vividas para extraer de ellas aprendizajes. Dichos aprendizajes, son pesquisados a partir de métodos y técnicas precisas que poseen una dimensión metodológica y procedimental. Por lo tanto, los procesos de formación en TS son claves en el traspaso creativo y cuidadoso de competencias para sistematizar.

- $\quad$ Si bien esta crisis sanitaria provoca alteraciones y desequilibrios sociales de alta escala, también se transforma en una oportunidad para sacar lo mejor de los seres humanos: expresiones de solidaridad, trabajo colectivo y respuestas que surgen desde el bien común. Las capacidades de resiliencia, los valores comunitarios y la organización social, constituyen valiosas herramientas de intervención social y es relevante aprehender dichas experiencias. En este sentido, existe una diferenciación entre distanciamiento físico y distanciamiento social. Son dos cosas distintas, donde la separación física no implica la ruptura de los vínculos e interacciones colaborativas.

- Desde lo virtual, reconociendo sus limitaciones y fronteras, es posible avanzar hacia acciones de intercambio y colaboración. Las interacciones y confianzas previas, son un potencial comunicador posible por fortalecer desde las posibilidades que implica el mundo virtual, como lo auditivo y visual. No sirve 
Sepúlveda-Hernández

la pasividad frente al medio tecnológico, sí la creatividad y consciencia de los aspectos conflictivos por reconducir.

- Esta crisis sanitaria, es una oportunidad para seguir construyendo un TS que transite desde el asistencialismo hacia procesos comunitarios respetuosos, pedagógicos y ético-políticos.

Agradecimientos: La autora agradece al profesor Oscar Jara Holliday, por su generosidad, por compartir sus saberes y hacer posible la realización de este artículo.

\section{Referencias bibliográficas}

Aguayo, C. (1992). Fundamentos teóricos de la sistematización. Revista de Trabajo Social, (61), 31-36.

Angel, J. L., \& Mudrazija, S. (2020). Local government efforts to mitigate the novel coronavirus pandemic among older adults. Journal of Aging and Social Policy, 32(4-5), 439-449. doi: 10.1080/08959420.2020.1771240.

Banks, S., Cai, T., de Jonge, E., Shears, J., Shum, M., Sobočan, A. .. Weinberg, M. (2020a). Ethical challenges for social workers during Covid-19: A global perspective. Rheinfelden, Switzerland: International Federation of Social Workers.

Banks, S., Cai, T., de Jonge, E., Shears, J., Shum, M., Sobočan, A. ... Weinberg, M. (2020b). Practising ethically during COVID-19: Social work challenges and responses. International Social Work, 63(5), 569-583. doi: 10.1177/0020872820949614.

Butler, J. (30 de marzo de 2020). Judith Butler discuss the COVID-19 pandemic, and its escalating political and social effects in America. Verso. Recuperado de https:/ / www.versobooks.com/blogs/4603-capitalism-has-its-limits.

Byung-Chun, H. (22 de marzo de 2020). La Emergencia viral y el mundo del mañana. El País. Recuperado de https://elpais.com/ideas/2020-03-21/la-emergencia-viral-y-elmundo-de-manana-byung-chul-han-el-filosofo-surcoreano-que-piensa-desdeberlin.html.

Center for Systems Science and Engineering. (2020). Tracking COVID-19. Recuperado de https://www.arcgis.com/apps/opsdashboard/index.html\#/bda7594740fd40299423 $467 \mathrm{~b} 48 \mathrm{e} 9 \mathrm{ecf} 6$.

Dauti, M., Dhëmbo, E., Bejko, E., \& Allmuça, M. (2020). Rethinking the transformative role of the social work profession in Albania: Some lessons learned from the response to COVID-19. International Social Work, 63(5), 640-645. doi: https://doi.org/10.1177/0020872820940356.

Firang, D. (2020). The impact of COVID-19 pandemic on international students in Canada. International Social Work, 63(6), 820-824 doi: 10.1177/0020872820940030. 
Sepúlveda-Hernández

Gallagher, H. L., Doherty, A. Z., \& Obonyo, M. (2020). International student experiences in Queensland during COVID-19. International Social Work, 63(6), 815-819. doi: $10.1177 / 0020872820949621$.

Henning-Smith, C. (2020). The unique impact of COVID-19 on older adults in rural areas. Journal of Aging and Social Policy, 32(4-5), 396-402. doi: https:/ / doi.org/10.1080/08959420.2020.1770036.

Jara-Holliday, O. (2013). La Sistematización de Experiencias, práctica y teoría para otros mundos posibles. Montevideo, Uruguay: EPPAL

Jara-Holliday, O. (2015). Producir conocimientos desde las prácticas de acción social de las universidades. Sistematización de experiencias de Extensión Universitaria en Costa Rica 2013-2014. La Piragua, Revista de Educación y Política, (41), 55-69.

Jara-Holliday, O. (2020). Systematisation of Experiences: New paths to academic work in universities. International Journal of Action Research, 16(1), 62-74.

Johns, L., Blackburn, P., \& McAuliffe, D. (2020). COVID-19, prolonged grief disorder and the role of social work. International Social Work, 63(5), 660-664. doi: $10.1177 / 0020872820941032$.

Klein, N. (8 de mayo de 2020). Screen New Deal. The Intercept. Recuperado de https://theintercept.com/2020/05/08/andrew-cuomo-eric-schmidt-coronavirustech-shock-doctrine/.

Levin-Dagan, N., \& Strenfeld-Hever, S. (2020). Reflections on Israeli hospital-based social work with COVID-19 patients and their families. International Social Work, 63(6), 766770. doi: https://doi.org/10.1177/0020872820952002.

Miller, V. J., \& Lee, H. (2020). Social work values in action during COVID-19. Journal of Gerontological Social Work. doi: 10.1080/01634372.2020.1769792.

Nisanci, A., Kahraman, R., Alcelik, Y., \& Kiris, U. (2020). Working with refugees during COVID-19: Social worker voices from Turkey. International Social Work, 63(5), 685-690. doi: $10.1177 / 0020872820940032$.

Nissen, L. (2020). Social work and the future in a post-COVID- 19 world: A foresight lens and a call to action for the profession. Journal of Technology in Human Services, 38(4), 309-330. doi: https:/ / doi.org/10.1080/15228835.2020.1796892.

Omorogiuwa, T. B. (2020). COVID-19 and older adults in Africa: Social workers' utilization of mass media in enforcing policy change. International Social Work, 63(5), 646-650. doi: https:/ / doi.org/10.1177/0020872820941748.

Organización para la Naciones Unidas. (2020). Informe de los Objetivos de Desarrollo Sostenible. Recuperado de https://unstats.un.org/sdgs/report/2020/TheSustainable-Development-Goals-Report-2020_Spanish.pdf.

Papouli, E., Chatzifotiou, S., \& Tsairidis, C. (2020). The use of digital technology at home during the COVID-19 outbreak: Views of social work students in Greece. Social Work Education, 39(8), 1107-1115. doi: https:// doi.org/10.1080/02615479.2020.1807496.

Programa de Naciones Unidas para el Desarrollo. (2020a). COVID-19: la pandemia. PNUD. Recuperado de https://www.undp.org/content/undp/en/home/coronavirus.html. 
Sepúlveda-Hernández

Programa de Naciones Unidas para el Desarrollo. (2020b). COVID-19: Human development on course to decline this year for the first time since 1990. Recuperado de http://hdr.undp.org/sites/default/files/eng_pr_human_development_on_course_t o_decline_for_the_first_time_since_1990_.pdf.

Rivera, C., Yu-Chieh, H., Pavez-Esbry, F., y Dugarova, E. (13 de julio de 2020). ¿Qué significa la COVID-19 para las mujeres? PNUD. Recuperado de https:/ /www.undp.org/content/undp/es/home/blog/2020/what-doescoronavirus-mean-for-women.html.

Segato, R. (19 de abril de 2020). Coronavirus: todos somos mortales. Del significante vacío a la naturaleza abierta de la historia. Lobo Suelto. Recuperado de http:/ / lobosuelto.com/todos-somos-mortales-segato/.

Sigüenza, C., y Rebollo, E. (12 de mayo de 2020). Byung-Chul Han: Viviremos como en un estado de guerra permanente. EFE. Recuperado de https://www.efe.com/efe/espana/destacada/byung-chul-han-viviremos-como-enun-estado-de-guerra-permanente/10011-4244280.

Smoyer, A. B., O’Brien, K., \& Rodríguez-Keyes, E. (2020). Lessons learned from COVID-19: Being known in online social work classrooms. International Social Work, 63(5), 651-654. doi: https:/ / doi.org/10.1177/0020872820940021.

Tapella, E., y Rodriguez-Bilella, P. (2014). Sistematización de experiencias: una metodología para evaluar intervenciones de desarrollo. Revista de Evaluación de Programas y Políticas Públicas, (3), 80-116. doi: 10.5944/reppp.3.2014.13361.

The Global Fund. (2020). Situations Reports. Recuperado de https://www.theglobalfund.org/en/covid-19/news/.

Žižek, S. (27 de febrero de 2020). Coronavirus es un golpe al capitalismo al estilo de 'Kill Bill' y podría conducir a la reinvención del comunismo. Russia Today. Recuperado de http://www.relats.org/documentos/FTLecturas.Zizek.abril.pdf. 


\section{OTROS ARTÍCULOS DE PROSPECTIVA No. 31 DE 2021}

\section{PRESENTACIÓN}

Presentación. Reflexiones sobre desafios al publicar sistematizaciones

Rosa María Cifuentes-Gil

\section{EDITORIAL}

Reflexiones sobre Trabajo Social: aportes de la Sistematización

María Rocío Cifuentes-Patiño

\section{ARTÍCULOS}

Hacer lo que se sabe, pensar lo que se hace. La sistematización como modalidad investigativa Alfonso Torres-Carrillo

Aportes y desafios de la Sistematización de experiencias en el Trabajo Social y la extensión crítica. Apuntes y reflexiones desde la perspectiva de la Educación Popular

María Rosa Goldar

Valeria Chiavetta

La sistematización en Trabajo Social y la epistemología feminista del punto de vista. Diálogos sobre la producción de conocimiento sustentada en experiencias

Ruth Noemí Parola

María Florencia Linardelli

La Sistematización investigativa de las experiencias: del baile de los que sobran a la fiesta de los que faltan

María Belén Ortega-Senet

Sistematización y Trabajo Social en Chile. El largo y sinuoso camino

Patricia Lorena Castañeda-Meneses

Ana María Salamé-Coulon
Sentipensar la pandemia COVID-19 desde la sistematización de la experiencia en Trabajo Social: reflexiones del profesor Oscar Jara Holliday

Elia Sepúlveda-Hernández

La sistematización de experiencias, una investigación social cualitativa que potencia buenas prácticas de convivencia y gobierno. La experiencia de un conjunto residencial multifamiliar en Cali, Colombia Martha Lucia Echeverry-Velásquez Manuela Prada-Dávila

Construcción de subjetividades epistemológicaspolíticas de profesoras y profesores de Investigación social en una universidad privada y confesional en Bogotá

Giovanni Mora-Lemus

Sistematización de la experiencia Reconocimiento de los derechos humanos del adulto mayor en dos familias residentes en Cali y Valledupar (Colombia)

Lina María Cuello-Lacouture

Jimena del Pilar Jaramillo-Jaramillo

La memoria transformadora como estrategia de intervención profesional en los procesos de reconciliación social: comprensión a partir de mujeres campesinas, excombatientes y jóvenes en Manizales, Colombia

Yeimmy Stephania Corredor-Sotelo

Juliana Fuertes-Fuertes

Sistematización de una estrategia de educación informal implementada en personas privadas de la libertad en el establecimiento penitenciario de mediana seguridad y carcelario de Barranquilla, Colombia

Rafael Humberto Herrera-Mercado Rafael Alberto Zambrano-Vanegas 
Aportes significativos del proceso de intervención comunitaria con la Escuela Popular de Comunicación Alternativa Jaime Garzón de la ciudad de Cúcuta, Colombia

Carlos Lasso-Urbano

La sistematización de la intervención como metodología de investigación en Trabajo Social. Importancia práctica y teórica de la fase de recogida de datos en la intervención social según experiencia del Programa de Apoyo a las Familias en Zaragoza, España

Elisa Esteban-Carbonell

Nuria Del Olmo-Vicén

Papel de la sistematización de experiencias en los procesos de evaluación de intervenciones de salud pública en la Comuna Saludable por la Paz, Cali - Colombia

Jenny Faisury Peña-Varón

Paola Andrea Marín-Velásquez

Janeth Mosquera-Becerra

Experiencia de intervención social en hogares comunitarios integrales del barrio Alfonso Bonilla Aragón, Cali - Colombia

Julián Alexander Montaño-Cárdenas

Las políticas sociales y el gobierno de la "población indígena". Estrategias y regulaciones en el multiculturalismo chileno

Rodrigo Agustín Navarrete-Saavedra

Representaciones sociales sobre estilo de autoridad y tipos de interacción en cuidadores de residencias de protección infantil en Chile

Marcelo Gallegos-Fuentes
Carmen Gloria Jarpa-Arriagada

Reflexiones sobre inseguridad social y cuestiones penales. Una respuesta estratégica a partir de experiencias de cooperativismo con ex detenidos en Argentina

Analia Elizabeth Otero

Yael Yanina Barrera

Desarrollo y salud: la emergencia de un nuevo paradigma

Jesús María Sánchez-Ordóñez

Trabajo Social en ejercicio libre: la perspectiva profesional en España

Paula Frieiro-Padín

Tamara Fernández-Arias

Rubén González-Rodríguez

\section{RESEÑAS}

Social Work and the City: Urban Themes in 21stCentury Social Work

Felipe Saravia-Cortés

Respuestas del Trabajo Social ante emergencias sociales y problemáticas sociales complejas de México y España

Felipe Saravia-Cortés

El feminismo, el género y la profesionalización del trabajo social en Colombia (1936-2004)

Ambar Oriana Serna-Lombo

El puño invisible. Arte, revolución y un siglo de cambios culturales

Carlos Arturo Robledo-Marín

\section{PROSPECTIVA}

No. $31 \bullet$ ene.-jun. 2021

e-ISSN: 2389-993X • Universidad del Valle 